Article

\title{
Beneficial Use of MIBC in Metakaolin-Based Geopolymers to Improve Flowability and Compressive Strength
}

\author{
Sujeong Lee ${ }^{1,2, *}$, Byoungkwan Kim ${ }^{2}$, Joobeom Seo ${ }^{1}$ and Shinhu Cho ${ }^{3}$ \\ 1 Mineral Resources Research Division, Korea Institute of Geoscience and Mineral Resources, Daejeon 34132, \\ Korea; joobeomi@kigam.re.kr \\ 2 Department of Resources Recycling Engineering, University of Science \& Technology, Daejeon 34113, Korea; \\ Kwan9282@gmail.com \\ 3 Advanced Materials Research Team, Hyundai Motor Group, Uiwang 16082, Korea; s.cho@hyundai.com \\ * Correspondence: crystal2@kigam.re.kr; Tel.: +82-42-868-3125; Fax: +82-42-868-3418
}

Received: 26 June 2020; Accepted: 17 August 2020; Published: 19 August 2020

\begin{abstract}
Superplasticizers (cement concrete water reducers) are applied to improve the flowability of calcium-rich, alkali-activated materials, with inconsistent results. However, superplasticizer applications are limited in metakaolin-based geopolymers. The possibility of using polycarboxylate superplasticizers and methyl isobutyl carbinol (MIBC) to ameliorate the flowability of metakaolin-based geopolymers was investigated. The ratio of metakaolin, fumed silica, $\mathrm{NaOH}$ or $\mathrm{KOH}$, and water in geopolymers at a $\mathrm{Na}_{2} \mathrm{O}$ or $\mathrm{K}_{2} \mathrm{O}: \mathrm{Al}_{2} \mathrm{O}_{3}: \mathrm{SiO}_{2}: \mathrm{H}_{2} \mathrm{O}$ ratio = 1:1:4:10 or 1:1:4:11 was maintained in the formulations. In this study, ether- or ester-based polycarboxylate superplasticizers did not improve the workability of fresh metakaolin-based Na-geopolymers. A low MIBC dose (0.5 wt.\% of metakaolin) improved the flowability by $19 \%$ and additionally increased the 7 -day compressive strength by $22 \%$ from 68 to $83 \mathrm{MPa}$ for plain Na-geopolymers. The entrained fine froths produced by adding MIBC during mixing likely reduced friction between metakaolin particles, and the slurry became more workable. Hence, the geopolymer mixture with an improved flowability became more homogenous, which ensured more extensive metakaolin dissolution and hydrolysis. A low MIBC dose could be effective for Na-geopolymers with dual benefits of improved workability and enhanced compressive strength.
\end{abstract}

Keywords: methyl isobutyl carbinol; flowability; metakaolin-based geopolymers; compressive strength

\section{Introduction}

Geopolymers, consisting of randomly disordered silicon and aluminum tetrahedrons bonded by oxygen atoms, are formed by combining an alkaline solution with reactive aluminosilicate powder, in particular, metakaolin or low-calcium fly ash, at ambient or low temperatures [1,2]. The primary application of geopolymers includes reduced- $\mathrm{CO}_{2}$ construction materials as an alternative to Portland-based cements [2], functioning as a monolithic refractory [3] and heat-resistant binder [4]. Geopolymers are typically synthesized from potassium or, more commonly, sodium as the alkali cation and are considered precursors to ceramic manufacturing [5,6]. Metakaolin-based geopolymers reacted with sodium activators have a higher viscosity than those reacted with potassium activators [7]. The high viscosity of sodium silicate solutions prohibits the thorough mixing required for producing a homogeneous slurry and reduces the workability. In terms of workability, potassium hydroxide is preferred over sodium hydroxide, but it is more expensive than sodium hydroxide. Sodium hydroxide is the most commonly used hydroxide activator in geopolymer synthesis, being both the cheapest and most widely available of the alkali hydroxides [2]. Therefore, an admixture is needed to increase the flowability of fresh metakaolin-based geopolymer paste made with sodium hydroxide. 
Cement particles are highly likely to agglomerate due to the attractive forces between fine particles. Cement particle flocculation or dispersion can influence the setting behavior, chemical shrinkage and capillary porosity depercolation by substantially decreasing the hydration degree at the initial setting time [8]. Various chemical admixtures have been developed in the cement concrete industry since the 1930s to reduce the water/cement ratio while maintaining a suitable workability and to produce stronger and more durable materials [9]. Superplasticizers are chemical admixtures used for reducing the water demand and are currently essential to cement concrete formulations. Polycarboxylates (PCEs) are comb-shaped superplasticizers and are known to dramatically reduce the water demand in cement concrete [9]. PCEs are steric admixtures, and their dispersing ability is due to steric hindrance effects rather than electrostatic repulsion [10]. Mutual repulsion of the particles is governed by the solubility of the polymeric tails in the liquid [10]. The steric hindrance is expected to affect geopolymers or alkali-activated materials. Geopolymers can have slightly higher $\mathrm{pH}$ values than ordinary Portland cement, and the chemical behavior of superplasticizers with various alkali activating solutions seems to be different than that of cement.

Many studies have added superplasticizers to calcium-rich precursors, such as blast furnace slag or high-calcium fly ash [11-20], but the use of superplasticizers in metakaolin- or low-calcium fly ash-based geopolymers activated by sodium hydroxide or silicates is very limited [21-24]. In addition, it has not been reported whether plasticizers or superplasticizers applied in geopolymers or alkali-activated materials function as efficiently as when they are applied in cement concrete. For instance, a recent study reported that the addition of a polycarboxylic ether-based superplasticizer improved the flowability of fly ash-based geopolymers without compromising the final strength of the hardened material, which was determined based on a performance assessment of a range of natural and synthetic polymers [10]. The flowability, however, was only slightly improved, and the effect of the additional water present in the superplasticizers was not even considered. The superior dispersing ability of superplasticizers is the key factor for the workability of high-performance and self-consolidating concrete with a water/cement ratio as low as 0.3 or lower [9]. If the flowability is only slightly improved, the use of superplasticizers does not satisfy their original purpose. Superplasticizers can have adverse effects on alkali-activated materials, such as retarding the activation process, failing to improve flowability and even reducing the mechanical strength of alkali-activated slag $[15,16,20,25]$. On the other hand, certain superplasticizers are not chemically stable, as evidenced by the precipitation of the sulfonated melamine formaldehyde superplasticizer in a $\mathrm{KOH}$ solution [26], or the rapid degradation in an alkaline environment [13,27]. In alkali-activated slag systems, the need to develop new chemically stable superplasticizers has emerged to enhance the flowability of slag cement at high pH levels [25].

This paper aims to evaluate the efficiency of the water-reducing performance of polycarboxylate superplasticizers and methyl isobutyl carbinol (MIBC) in metakaolin-based geopolymers activated with sodium hydroxide. The geopolymers investigated here were produced through room-temperature activation of metakaolin with sodium hydroxide and fumed silica. By dissolving fumed silica in an $\mathrm{NaOH}$ solution, the optimum formulation of metakaolin-based geopolymers [28] can be achieved. MIBC, which has not been used in metakaolin-based geopolymer systems, and three PCEs were applied during the mixing process. In addition, the compressive strength values of pure Na- and K-geopolymers at different water contents and MIBC-containing Na-geopolymers are compared.

\section{Material and Methods}

\subsection{Characterization of Metakaolin}

Metakaolin MetaMax (BASF, Ludwigshafen, Germany) was adopted to produce geopolymers cured at ambient temperature. X-ray diffraction (XRD) patterns of the representative metakaolin samples were obtained with a D8 Advance diffractometer (Bruker-AXS, Karlsruhe, Germany) over a $2 \theta$ range from 5 to $80^{\circ}$. The metakaolin was milled in a micronizing mill (McCrone, Westmont, IL, USA) for $5 \mathrm{~min}$ prior to XRD. 
The chemical composition of the metakaolin was analyzed via X-ray fluorescence spectroscopy (Shimadzu Sequential XRF-1800, Shimadzu, Kyoto, Japan). Three representative samples were prepared as fused beads, and the average of three measurements of the $\mathrm{Al}_{2} \mathrm{O}_{3}$ and $\mathrm{SiO}_{2}$ contents was calculated to formulate geopolymers.

To ensure representative sampling, a sieving riffler manufactured by Quantachrome Instruments (Boynton Beach, FL, USA) was used.

\subsection{Geopolymer Synthesis and Characterization}

The chemical composition of the metakaolin-based geopolymers was proposed as $\mathrm{M}_{2} \mathrm{O}: \mathrm{Al}_{2} \mathrm{O}_{3}: 4 \mathrm{SiO}_{2}: 11 \mathrm{H}_{2} \mathrm{O}$ or simply as 1:1:4:11 based on previous transmission electron microscopy (TEM) studies, where $\mathrm{M}$ is a charge-balancing cation, such as $\mathrm{Na}^{+}$and $\mathrm{K}^{+}$[28]. The $\mathrm{Si}$ to $\mathrm{Al}$ ratio in this formula is 2.0, and the $\mathrm{Na}$ to $\mathrm{Al}$ ratio is 1.0 . The 1:1:4:11 formula was primarily adopted in this study for producing geopolymer paste. The formula was modified to 1:1:4:10 to validate the improvement of the geopolymer mixture flowability (Table 1).

Table 1. Mixture design of metakaolin-based geopolymers with admixtures. Spread diameter of the fresh geopolymer mixtures was expressed in mm. Methyl isobutyl carbinol (MIBC) gave better performance in terms of flowability, but the higher amount of admixtures resulted in the inverse effect. The slurry of 1:1:4:10 K-geopolymer overflowed from the disc and its flow diameter was assumed to be more than $254 \mathrm{~mm}$.

\begin{tabular}{|c|c|c|c|c|c|}
\hline \multirow[t]{2}{*}{$\begin{array}{c}\mathrm{M}_{2} \mathrm{O}: \mathrm{Al}_{2} \mathrm{O}_{3}: \mathrm{SiO}_{2}: \mathrm{H}_{2} \mathrm{O} \\
(\mathrm{M}=\mathrm{Na} \text { or } \mathrm{K})\end{array}$} & \multirow{2}{*}{ Alkaline Activator } & \multicolumn{2}{|c|}{ Admixture } & \multirow{2}{*}{ Water Content (wt.\%) } & \multirow{2}{*}{ Flow Diameter (mm) } \\
\hline & & Type & $\begin{array}{l}\text { Dose by Weight of } \\
\text { Metakaolin (wt.\%) }\end{array}$ & & \\
\hline \multirow{7}{*}{ 1:1:4:10 } & & $\begin{array}{c}\text { PCE 1 } \\
\text { (ester-based) }\end{array}$ & 5.1 & 31.3 & $144( \pm 4.12)$ \\
\hline & & \multirow{4}{*}{$\begin{array}{c}\text { PCE 3 } \\
\text { (ether-based) }\end{array}$} & 0.3 & 30.3 & $163( \pm 9.39)$ \\
\hline & & & 0.5 & 30.4 & $163( \pm 3.05)$ \\
\hline & & & 1.0 & 30.5 & $157( \pm 7.47)$ \\
\hline & & & 5.1 & 31.3 & $145( \pm 7.81)$ \\
\hline & & \multirow{2}{*}{ MIBC } & 5.1 & 31.6 & $179( \pm 1.05)$ \\
\hline & & & 10.2 & 33.0 & $175( \pm 1.30)$ \\
\hline 1:1:4:10 & $\mathrm{KOH}+$ fumed silica & - & - & & $>254$ \\
\hline 1:1:4:11 & $\mathrm{NaOH}+$ fumed silica & - & - & 32.4 & $227( \pm 2.60)$ \\
\hline
\end{tabular}

Sodium hydroxide (Daejung Chemical, assay 97\%, Siheung-si, Korea) or potassium hydroxide (Daejung Chemical, assay 93\%, Siheung-si, Korea) was dissolved in distilled water using a magnetic stirrer. After the sodium hydroxide or potassium hydroxide solution was cooled, fumed silica $\left(\mathrm{SiO}_{2}\right.$, CAB-O-SIL EH-5, Cabot Corporation, assay $99.99 \%$, Boston, MA, USA) was added to the $\mathrm{NaOH}$ or $\mathrm{KOH}$ solution. Metakaolin was mixed with an alkali activator solution at a low speed for $2 \mathrm{~min}$ and at a high speed for 5 min with a Kenwood mixer. The chemical additives were added to the mixture before high-speed mixing.

The geopolymer mixture was then poured into 5 - $\mathrm{cm}$ cube molds and cured at ambient temperature for 7 days after synthesis. The mean compressive strength of the three samples was measured with an MTS 815 rock mechanics test system (460 tons) at a loading rate of $5.5 \times 10^{-3} \mathrm{~mm} / \mathrm{s}$ (MTS Systems Corporation, Eden Prairie, MN, USA). 


\subsection{Characterization of the Chemical Additives}

Commercial superplasticizers based on polycarboxylate polymers (PCE 1, PCE 2, and PCE 3) produced in Korea and an aliphatic alcohol, i.e., MIBC (4-methyl-2-pentanol, assay 98\%, Sigma-Aldrich, Saint Louis, MO, USA) were tested as water reducers in metakaolin-based geopolymers. PCE 1, PCE 2 and PCE 3 are pale amber-colored liquids, and MIBC is transparent.

The solids content of the superplasticizers was determined by subtracting the amount of evaporated water at $160{ }^{\circ} \mathrm{C}$ for $30 \mathrm{~min}$ from the total sample weight, i.e., $2 \mathrm{~g}$, as determined with a moisture analyzer (MB 45, OHAUS, Parsippany, NJ, USA). The solids fraction of the superplasticizers was used for Fourier transform infrared spectrometry (FT-IR). Fifteen grams of superplasticizer was immersed in a rotating flask and dried in a water bath designed to maintain the liquid temperature at $80^{\circ} \mathrm{C}$ until the water fraction of the superplasticizer was completely evaporated under vacuum. Attenuated total reflectance (ATR)-FT-IR spectra were obtained (Nicolet 6700, Thermo Fisher Scientific, Waltham, MA, USA) over the range of $4000-650 \mathrm{~cm}^{-1}$.

\subsection{Evaluation of the Flowability}

The flowability of the fresh geopolymer mixtures was evaluated via the flow table test in accordance with KS L 5111. The flow mold was lifted $1 \mathrm{~min}$ after geopolymer addition, and the spread diameter was measured after dropping the table 25 times over $15 \mathrm{~s}$ (Figure 1a). The average flow diameter was calculated from four spread diameter measurements from D1 to D4 (Figure 1b).

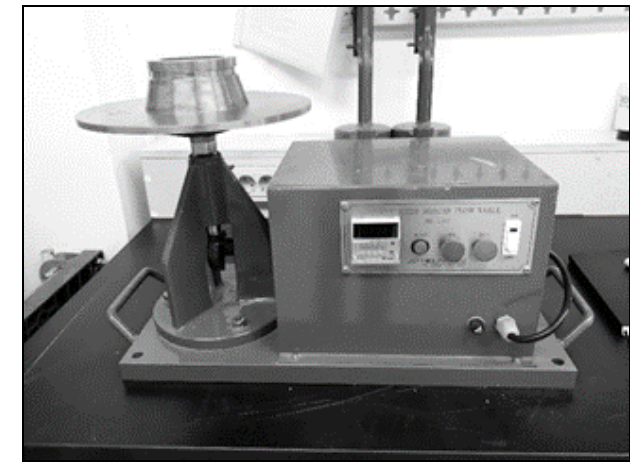

(a)

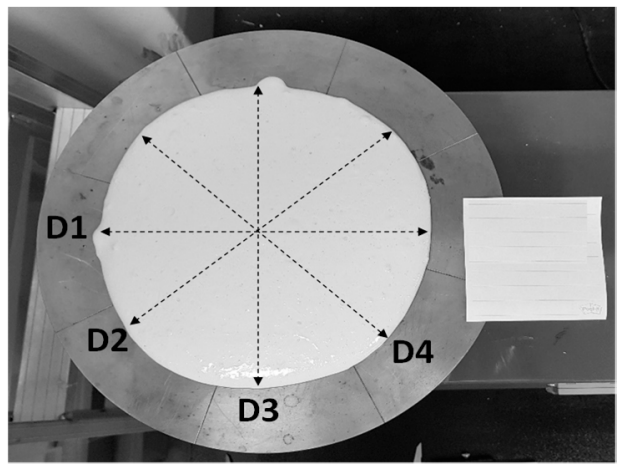

(b)

Figure 1. (a) Motorized flow table for flowability testing. The conical mold has a $100-\mathrm{mm}$ base diameter, 70-mm top diameter and 50-mm height. (b) The average of the four spread diameter values from D1 to D4 is presented as the flow diameter in Table 1.

\section{Results and Discussion}

\subsection{Characteristics of the Metakaolin}

XRD revealed that the tested metakaolin contained amorphous and crystalline phases, including quartz, illite and anatase (Figure 2). The major chemical composition of metakaolin was $\mathrm{SiO}_{2}$ and $\mathrm{Al}_{2} \mathrm{O}_{3}$ (Table 2). The theoretical composition of anhydrous metakaolin is $54.0 \% \mathrm{SiO}_{2}$ and $46.0 \% \mathrm{Al}_{2} \mathrm{O}_{3}$ based on the theoretical composition of kaolinite, which is composed of $46.54 \%$ $\mathrm{SiO}_{2}, 39.50 \% \mathrm{Al}_{2} \mathrm{O}_{3}$ and $13.96 \% \mathrm{H}_{2} \mathrm{O}$ [29]. The $\mathrm{SiO}_{2}$ and $\mathrm{Al}_{2} \mathrm{O}_{3}$ concentrations of $52.6 \%$ and $43.8 \%$, respectively, were considered to be fully reactive for formulating geopolymers, even though these values include small amounts of crystalline $\mathrm{SiO}_{2}$ and $\mathrm{Al}_{2} \mathrm{O}_{3}$ as quartz and illite, respectively. 
Table 2. Content of the major elements in the metakaolin used in this study, as determined by X-ray diffraction (XRD).

\begin{tabular}{cccccccccccc}
\hline Oxide & $\mathrm{SiO}_{2}$ & $\mathrm{Al}_{2} \mathrm{O}_{3}$ & $\mathrm{Fe}_{2} \mathrm{O}_{3}$ & $\mathrm{CaO}$ & $\mathbf{M g O}$ & $\mathrm{K}_{2} \mathrm{O}$ & $\mathrm{Na}_{2} \mathrm{O}$ & $\mathrm{TiO}_{2}$ & $\mathbf{M n O}$ & $\mathbf{P}_{2} \mathrm{O}_{5}$ & Others \\
\hline wt. $\%$ & 52.6 & 43.8 & 0.30 & 0.03 & 0.09 & 0.16 & 0.35 & 1.49 & 0.01 & 0.08 & 0.93 \\
\hline
\end{tabular}

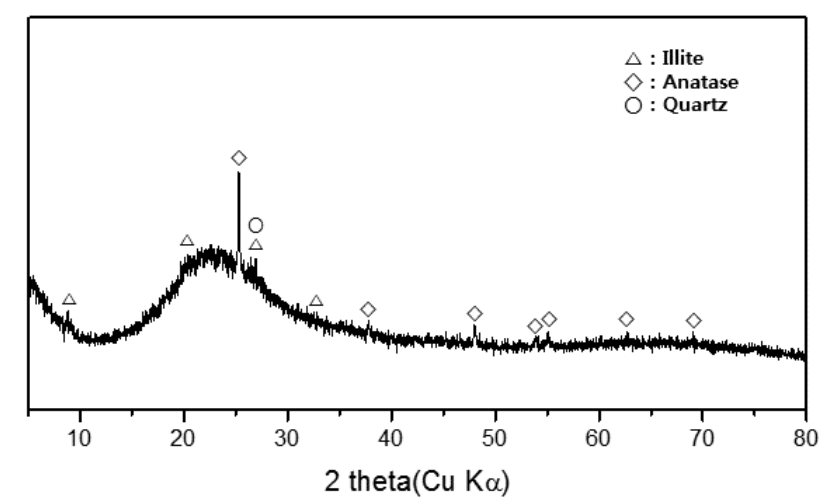

Figure 2. X-ray diffraction pattern of the metakaolin used in this study. It contains crystalline phases such as illite (an aluminosilicate), anatase and quartz (crystalline silica).

\subsection{Characteristics of the Chemical Additives}

The $\mathrm{C}=\mathrm{O}$ stretching vibration band at $1730 \mathrm{~cm}^{-1}$ in the FT-IR spectra of PCE 1 and PCE 2 indicated that they were ester-based superplasticizers [30] (Figure 3). PCE 3 was estimated to consist of an ether structure because of the asymmetric stretching of C-O-C at $1100 \mathrm{~cm}^{-1}$, while the band at approximately $1570 \mathrm{~cm}^{-1}$ presumably occurred due to $\mathrm{COO}^{-}$and $\mathrm{Na}^{+}[31,32]$. The bands at 2880,1466 and $1340 \mathrm{~cm}^{-1}$ were assigned to the $\mathrm{C}-\mathrm{H}$ stretching vibration [32].

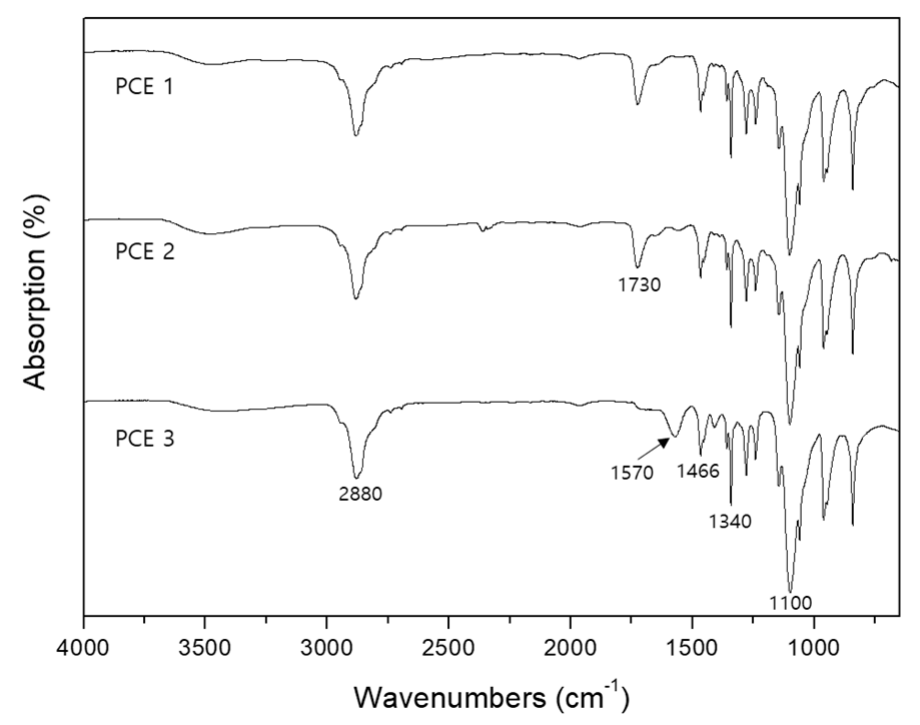

Figure 3. FT-IR spectra of the polycarboxylate superplasticizers used in this study. Superplasticizers PCE 1 and PCE 2 contain ester side chains, while PCE 3 includes ether side chains.

The solids content of the PCEs was approximately $16 \%$ for PCEs 1 and 2 and approximately $18 \%$ for PCE 3 . This means that additional water is introduced to the metakaolin-based geopolymer mixture, depending on the PCE dose. The resultant final water content in the geopolymer mixtures was calculated to consider the water content in the superplasticizers (Tables 1 and 3). The MIBC amount was included in the water content, depending on its dose. 
Table 3. The water content in each mixture, including the free water in the mixture proportions and the chemical water in the alkali hydroxides, is recalculated to encompass the water content in the polycarboxylates. A low MIBC dose is beneficial to both the flowability and strength development.

\begin{tabular}{ccc}
\hline Geopolymers & Water Content (wt.\%) & Compressive Strength (MPa) \\
\hline 1:1:4:10 Na-GP & 30.3 & $68 \pm 4.6$ \\
\hline 1:1:4:10 Na-GP with MIBC 0.5\% & 30.4 & $83 \pm 6.0$ \\
\hline 1:1:4:11 Na-GP & 32.4 & $59 \pm 2.5$ \\
\hline 1:1:4:10 K-GP & 32.3 & $62 \pm 4.6$ \\
\hline
\end{tabular}

\subsection{Flowability Enhancement Induced by MIBC}

The flowability of the fresh geopolymers deteriorated as the water content decreased. The spread diameter of the 1:1:4:11 Na-geopolymer with a water content of $32.4 \%$ was $227 \mathrm{~mm}$ and dropped to $159 \mathrm{~mm}$ for the 1:1:4:10 Na-geopolymer with a water content of 30.3\% (Table 1). The PCE superplasticizers used in this study, PCEs 1, 2 and 3, had little effect on increasing the workability, not only at a metakaolin dose of $5.1 \mathrm{wt} . \%$ but also at lower doses (Table 1). When PCE 3 was added at a dosage of $10.2 \%$, the spread diameter increased to $171 \mathrm{~mm}$. However, the additional water present in the PCE solution contributed to the total water content of the mixture $(32.3 \%)$ and eventually resulted in a better workability (Table 1). When PCE 3 was added at low dosages, namely, 0.3, 0.5 and 1.0\%, the spread diameters were not very different from those of the pure geopolymers (Table 1).

Geopolymers attain a far lower yield stress than typical cement paste [33]. Particularly, the cohesion of the calcium-silicate-hydrate (C-S-H) phase is much stronger than the cohesion of the early aluminosilicate gel produced in the geopolymer reaction, and superplasticizers have no effect on geopolymer paste [33]. Metakaolin-based geopolymers can be described as Newtonian fluids, as their viscosity is mainly controlled by the high viscosity of the suspending alkaline silicate solution and not by the contribution of the direct contacts between metakaolin particles [33]. Moreover, it has been verified that sodium ions predominantly induce entropic repulsion, while calcium ions give rise to strong electrostatic coupling in lamellar materials, including hydrated cements and clays [34]. The dispersal ability of superplasticizers is due to electrostatic repulsion or steric hindrance rather than entropic repulsion [11]. Entropic repulsion differs from charge repulsion, realizing particle dispersion and preventing flocculation by steric or entropic effects [35]. Because of the fundamental differences between metakaolin-based Na-geopolymers and ordinary Portland cement, the addition of PCEs can be considered to be ineffective. The results shown in Table 3 also support this assumption.

A low dose $(0.5 \%)$ of MIBC increased the spread diameter of the geopolymer mixture from 159 to $190 \mathrm{~mm}$ (Table 1). A dose that was twice as high produced a slightly smaller spread diameter of $184 \mathrm{~mm}$ (Table 1). The spread diameters decreased at high doses, in contrast to what occurred at low doses (Table 1). MIBC is an aliphatic alcohol containing 6 carbon atoms, and has been used to generate bubbles and stabilize froth during froth flotation of minerals in the mining industry [36]. The action of aliphatic alcohols such as MIBC remains elusive despite their many years of industrial use [37]. Although there is no ready explanation for the improvement mechanism, the metakaolin-based geopolymers containing $0.5 \%$ MIBC clearly became much more workable than pure geopolymers. One possible reason for the improvement effect of MIBC on metakaolin-based geopolymers is that the fine froths, entrained by adding MIBC during mixing, likely reduced friction between metakaolin particles, and the slurry could further spread. MIBC has limited solubility in water, and consequently, adding MIBC in high doses reduced the flow diameter (Table 1), and the extra amount of MIBC, which is insoluble in water, was separated. 


\subsection{Additional Benefit of MIBC on the Compressive Strength}

The mean 7-day compressive strength of three 1:1:4:10 Na-geopolymer specimens was $68 \mathrm{MPa}$ (Table 3). With increasing water contents, the compressive strength of the 1:1:4:11 Na-geopolymer decreased to $59 \mathrm{MPa}$. A lower water content results in a more compact structure and the development of a higher strength $[2,38,39]$. When MIBC was added at a dose of $0.5 \%$, the compressive strength of the 1:1:4:10 Na-geopolymer increased by $22 \%$ from 68 to $83 \mathrm{MPa}$ for pure geopolymers. Compared with the compressive strength of 1:1:4:10 K-geopolymers, namely, $62 \mathrm{MPa}$, adding $0.5 \% \mathrm{MIBC}$ to 1:1:4:10 Na-geopolymers was more beneficial in terms of the increased strength and cost competitiveness.

The microstructure consisting of dense particulates was achieved for both specimens (Figure 4). The addition of MIBC, however, made no perceptible difference in the microstructural evolution of the fresh fracture surfaces of geopolymers, even though the compressive strength increased by $22 \%$ (Figure 4). Good mixing is important to obtain homogeneous specimens and to avoid the agglomeration of the mixture for accelerating geopolymerization [40]. The homogeneity of the geopolymer mixtures was crucial to attain a high strength [41]. There is no clear explanation for how MIBC enhanced the compressive strength of geopolymers, but the MIBC-containing geopolymer mixture, with an improved flowability, was likely to be more homogeneous and cohesive than the highly viscous and sticky pure geopolymer mixture. The enhanced homogeneity, caused by the addition of MIBC, ensured the more extensive dissolution and hydrolysis of metakaolin particles. Another possible explanation for the action of MIBC on compressive strength is that less air might be entrapped when the slurry was placed into the molds because of the low viscosity of the slurry. This resulted in decreasing the porosity of the hardened geopolymers, increasing the compactness of the microstructure and, as a result, improving the strength.

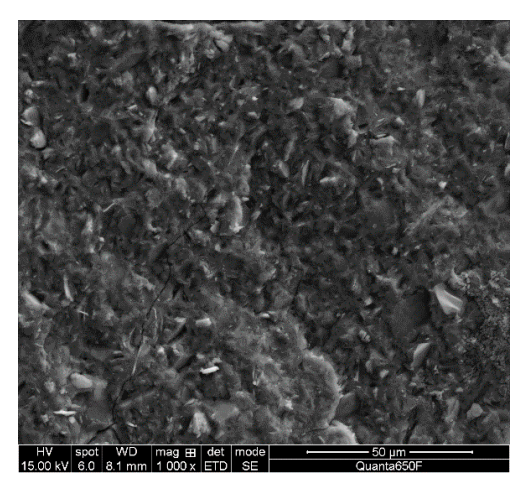

(a)

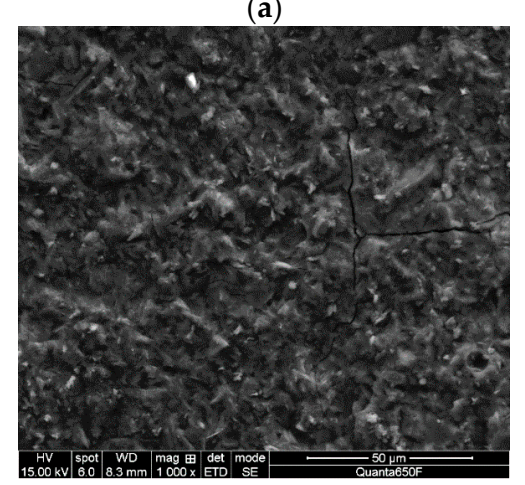

(c)

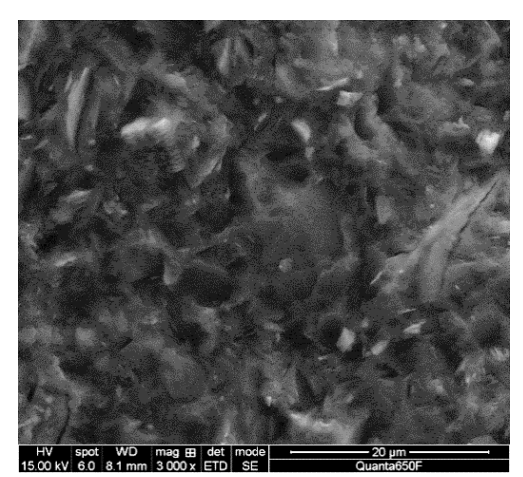

(b)

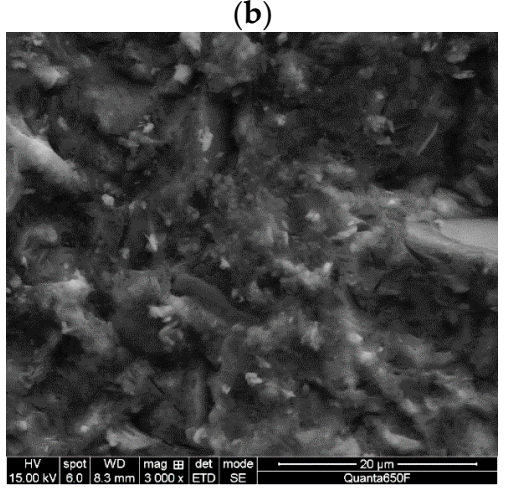

(d)

Figure 4. SEM micrographs of fresh fracture surfaces of the Na-geopolymers having a strength of $68 \mathrm{MPa}$ $(\mathbf{a}, \mathbf{b})$ and MIBC-containing Na-geopolymers having a strength of $83 \mathrm{MPa}(\mathbf{c}, \mathbf{d})$. Both specimens exhibit a microstructure comprising dense particulates. No meaningful difference between the microstructures of the fresh fracture surfaces was observed. Cracks could be created during sample preparation or while observing the samples under the high vacuum of SEM. 
As previously mentioned, the geopolymer ingredients were mixed at a high speed for only $5 \mathrm{~min}$ in this study, which does not represent thorough mixing. If a high-shear mixer is used with the same formulations, the compressive strength is expected to increase.

\section{Conclusions}

In this study, ether- or ester-based polycarboxylate superplasticizers did not improve the workability of fresh metakaolin-based Na-geopolymers. An aliphatic alcohol, MIBC, improved the flowability of fresh metakaolin-based Na-geopolymer mixtures with an additional strength enhancement effect when $0.5 \mathrm{wt} . \%$ metakaolin was added. MIBC did not dramatically reduce the water demand compared to PCEs in cement concrete, but the spread diameter increased by $19 \%$ after adding MIBC. The average 7-day compressive strength after synthesis was $68 \mathrm{MPa}$ for the 1:1:4:10 Na-geopolymer. Although the 1:1:4:10 K-geopolymer was much more workable than the 1:1:4:10 Na-geopolymer, the 1:1:4:10 K-geopolymer developed a lower strength of $62 \mathrm{MPa}$. By adding $0.5 \%$ MIBC by weight of metakaolin, the geopolymer mix was less workable than the K-geopolymer, but it developed a much higher strength, i.e., $83 \mathrm{MPa}$. The entrained fine froths, obtained by adding MIBC during mixing, likely reduced friction between metakaolin particles, and the slurry became more workable. As a result, the geopolymer mix with an improved flowability became more homogenous, which ensured the more extensive dissolution and hydrolysis of metakaolin particles at the early stage of geopolymerization. These results reveal that MIBC, at a low dose, could be effective when added to Na-geopolymers due to the dual benefits of an improved workability and enhanced compressive strength.

Author Contributions: S.L. contributed to conception, design, data analysis, writing -review and editing and funding acquisition; B.K. contributed to data analysis, visualization and original draft preparation; J.S. contributed to data analysis and original draft preparation; S.C. contributed to conception and funding acquisition. All authors have read and agreed to the published version of the manuscript.

Funding: This work is supported by a research grant from the Hyundai Motor Group; project title: Development of geopolymer composites for 3D printing and KIGAM; project title: Development of concentration, refining, and utilization processes for domestic vanadium ore.

Conflicts of Interest: The authors declare no conflict of interest.

\section{References}

1. Davidovits, J. Geopolymers: Inorganic polymeric new materials. J. Therm. Anal. Calorim. 1991, 37, 1633-1656. [CrossRef]

2. Provis, J.L.; van Deventer, J.S.J. Geopolymers: Structure, Processing, Properties and Industrial Applications; Woodhead: Oxford, UK, 2009.

3. Bansal, N.P.; Singh, J.P.; Kriven, W.M.; Schneider, H. Composite cold ceramic geopolymer in a refractory application. In Advances in Ceramic Matrix Composites IX, Proceedings of the 105th Annual Meeting of the American Ceramic Society, Nashville, TN, USA, 27-30 April 2003; Comrie, D.C., Kriven, W.M., Eds.; The American Ceramic Society: Westerville, OH, USA, 2003; Volume 153, pp. 211-225. [CrossRef]

4. Krivenko, P.V.; Kovalchuk, G.Y. Directed synthesis of alkaline aluminosilicate minerals in a geocement matrix. J. Mater. Sci. 2007, 42, 2944-2952. [CrossRef]

5. Iwahiro, T.; Nakamura, Y.; Komatsu, R.; Ikeda, K. Crystallization behavior and characteristics of mullites formed from alumina-silica gels prepared by the geopolymer technique in acidic conditions. J. Eur. Ceram. Soc. 2001, 21, 2515-2519. [CrossRef]

6. Bell, J.; Driemeyer, P. Formation of ceramics from metakaolin-based geopolymers. Part II: K.-based geopolymer. J. Am. Ceram. Soc. 2009, 92, 607-615. [CrossRef]

7. Sabitha, D.; Dattatreya, J.K.; Sakthivel, N.; Bhuvaneshwari, M.; Sathik, S.A.J. Reactivity, workability and strength of potassium versus sodium-activated high volume fly ash-based geopolymers. Curr. Sci. 2012, 103, 1320-1327.

8. Zheng, J.-J.; Zhang, J.; Scherer, G. Prediction of the degree of hydration at initial setting time of cement paste with particle agglomeration. Cem. Concr. Res. 2012, 42, 1280-1285. [CrossRef] 
9. Aïtcin, P.-C. The importance of the water-cement and water-binder ratios. In Science and Technology of Concrete Admixtures; Aïtcin, P.-C., Flatt, R.J., Eds.; Woodhead Publishing: Oxford, UK, 2016; pp. 3-13.

10. Carabba, L.; Manzi, S.; Bignozzi, M.C. Superplasticizer addition to carbon fly ash geopolymers activated at room temperature. Materials 2016, 9, 586. [CrossRef] [PubMed]

11. Gelardi, G.; Mantellato, S.; Marchon, D.; Placios, M. Chemistry of chemical admixtures. In Science and Technology of Concrete Admixtures; Aïtcin, P.-C., Flatt, R.J., Eds.; Woodhead Publishing: Oxford, UK, 2016; pp. 149-218.

12. Bakharev, T.; Sanjayan, J.G.; Chgeng, Y.B. Effect of admixtures on properties of alkali-activated slag concrete. Cem. Concr. Res. 2000, 30, 1367-1374. [CrossRef]

13. Yilmaz, V.T.; Odabađ̆oǵlu, M.; İçbudak, H.; Ölmez, H. The degradation of cement superplasticizers in a high alkaline solution. Cem. Concr. Res. 1993, 23, 152-156. [CrossRef]

14. Douglas, E.; Brandstetr, J. A preliminary study on the alkali activation of ground granulated blast-furnace slag. Cem. Concr. Res. 1990, 20, 746-756. [CrossRef]

15. Yang, K.-H.; Song, J.K.; Lee, J.-S. Properties of alkali-activated mortar and concrete using lightweight aggregates. Mater. Struct. 2010, 43, 403-416. [CrossRef]

16. Palacios, M.; Puertas, F. Effect of superplasticizer and shrinkage-reducing admixtures on alkali-activated slag pastes and mortars. Cem. Concr. Res. 2005, 35, 1358-1367. [CrossRef]

17. Palacios, M.; Banfill, P.F.; Puertas, F. Rheology and setting of alkali-activated slag pastes and mortars: Effect of organic admixture. ACI Mater. J. 2008, 105, 140-148.

18. Wang, Q.; Li, L.; Wu, C.P.; Sui, Z.T. Research on adaptability of slag-based geopolymer with superplasticizer. Key Eng. Mater. 2009, 405, 129-134. [CrossRef]

19. Puertas, F.; Palomo, A.; Fernández-Jiménez, A.; Izquierdo, J.; Granizo, M. Effect of superplasticisers on the behaviour and properties of alkaline cements. Adv. Cement Res. 2003, 15, 23-28. [CrossRef]

20. Muhammad, F.; Huang, X.; Li, S.; Xia, M.; Zhang, M.; Liu, Q.; Hassan, M.A.S.; Jiao, B.; Yu, L.; Li, D. Strength evaluation by using polycarboxylate superplasticizer and solidification efficiency of $\mathrm{Cr}^{6+}, \mathrm{Pb}^{2+}$ and $\mathrm{Cd}^{2+}$ in composite based geopolymer. J. Clean. Prod. 2018, 188, 807-815. [CrossRef]

21. Placios, M.; Houst, Y.F.; Bowen, P.; Puertas, F. Adsorption of superplasticizer admixtures on alkali-activated slag pastes. Cem. Concr. Res. 2009, 39, 670-677. [CrossRef]

22. Hardjito, D.; Wallah, S.E.; Sumajouw, D.M.J.; Rangan, B.V. On the development of fly ash-based geopolymer concrete. ACI Mater. J. Am. Concrete Inst. 2004, 101, 467-472.

23. Hardjito, D.; Wallah, S.E.; Sumajouw, D.M.; Rangan, B.V. Fly ash-based geopolymer concrete. Aust. J. Struct. Eng. 2005, 6, 77-86. [CrossRef]

24. Nematollahi, B.; Sanjayan, J. Effect of superplasticizers on workability of fly ash based geopolymer. In Proceedings of the International Civil and Infrastructure Engineering Conference, Kuching, Malaysia, 22-25 September 2013; pp. 375-378.

25. Hardjito, D.; Rangan, B. Development and properties of Low Calcium Fly Ash Based Geopolymer Concrete; Curtin University Research Report GC-1; Curtin University of Technology: Perth, Australia, 2005; pp. 51-54.

26. Provis, J.L.; van Deventer, J.S.J. Alkali Activated Materials: State-of-the-Art-Report; Springer: Berlin, Germany, 2014; pp. 145-156.

27. Nematollahi, B.; Sanjayan, J. Efficacy of available superplasticizers on geopolymers. Res. J. Appl. Sci. Eng. Tech. 2014, 7, 1278-1282. [CrossRef]

28. Kriven, W.M. Inorganic polysialates or 'geopolymers'. Am. Ceram. Soc. Bull. 2010, 89, 31-34.

29. Grim, R.E. Clay Mineralogy; McGraw Hill Book Company Incorporated: New York, NY, USA, 1953.

30. Smith, B.C. The $\mathrm{C}=\mathrm{O}$ bond, part VI: Esters and the rule of three. Spectroscopy 2018, 33, 20-23.

31. Ding, J.; Song, B.; Wang, C.; Xu, J.; Wu, Y. Synthesis and characterization of sodium nonylphenol ethoxylate (10) sulfoitaconate esters. J. Surfactants Deterg. 2010, 14, 43-49. [CrossRef]

32. Wang, J.; Zheng, G.; Yuan, M.; Sun, C.; Bi, Y. Effect of the initial temperature on the water-reducing performance of polycarboxylate-based superplasticizers. In Proceedings of the 2015 International Conference on Materials, Environmental and Biological Engineering, Guilin, China, 28-30 March 2015.

33. Favier, A.; Hot, J.; Habert, G.; Roussel, N.; de Lacaillerie, J.-B.E. Flow properties of MK-based geopolymer pastes. A comparative study with standard Portland cement pastes. Soft Matter 2014, 10, 1134-1141. [CrossRef] [PubMed] 
34. Pellenq, R.J.M.; Caillol, J.M.; Delville, A. Electrostatic attraction between two charged surfaces: A (N,V,T) monte carlo simulation. J. Phys. Chem. B 1997, 101, 8584-8594. [CrossRef]

35. Auschra, C.; Eckstein, E.; Mühlebach, A.; Zink, M.-O.; Rime, F. Design of new pigment dispersants by controlled radical polymerization. Prog. Org. Coat. 2002, 45, 83-93. [CrossRef]

36. Pugh, R.J. The physics and chemistry of frothers. In Froth Flotation: A Century of Innovation; Fuerstenau, M.C., Jameson, G., Yoon, R.H., Eds.; SME: Englewood, CO, USA, 2007; pp. 259-281.

37. Rao, S.R.; Leja, J. Surface Chemistry of Froth Flotation, Volume 2: Reagents and Mechanisms; Kluwer Academic/Plenum Publishers: New York, NY, USA, 2004.

38. Xie, J.; Kayali, O. Effect of initial water content and curing moisture conditions on the development of fly ash-based geopolymers in heat and ambient temperature. Constr. Build. Mater. 2014, 67, 20-28. [CrossRef]

39. Jansen, M. Effect of Water-Solids Ratio on the Compressive Strength, Degree of Reaction and Microstructural Characterization of Fly Ash-Waste Glass-Based Geopolymers. Master's Thesis, University of Minnesota, Minesota, MN, USA, 2017.

40. Gyekenyesi, A.; Kriven, W.M.; Wang, J.; Widjaja, S.; Singh, D. Developments in Strategic Materials and Computational Design, 2nd ed.; Wiley: New York, NY, USA, 2011.

41. Saleh, H.E.-D.; Rahman, R.A. Cement Based Materials. In Clay-Based Materials in Geopolymer Technology; Abdullah, M.M.A.B., Ming, L.Y., Yong, H., Tahir, M.F.M., Eds.; IntechOpen: London, UK, 2018.

(C) 2020 by the authors. Licensee MDPI, Basel, Switzerland. This article is an open access article distributed under the terms and conditions of the Creative Commons Attribution (CC BY) license (http://creativecommons.org/licenses/by/4.0/). 